Gut, 1972, 13, 191-196

\title{
Permeability and selectivity of canine and human jejunum during cholera
}

\author{
JON E. ROHDE ${ }^{1}$ AND LINCOLN C. CHEN \\ From the Pakistan-SEATO Cholera Research Laboratory, Dacca, East Pakistan
}

SUMMARY Increased permeability of the intestinal mucosa to small molecules and ions has previously been proposed as a mechanism causing the profuse diarrhoea characteristic of Asiatic cholera. A technique for measuring absorption rates of ${ }^{14} \mathrm{C}$-urea and ${ }^{3} \mathrm{H}$-arabinose has been employed to study jejunal permeability during experimental canine and naturally acquired human cholera. The ratio of the absorption rates of these two solutes of different size is an expression of intestinal membrane selectivity and permits calculation of an equivalent pore radius. No change of membrane selectivity was observed in canine loops after challenge with cholera toxin. During naturally acquired human cholera, jejunal pore size was not significantly different from that measured during convalescence. This method was demonstrated to be sensitive to changes induced by amphotericin B, an antibiotic known to alter membrane permeability and selectivity. These data are inconsistent with the hypothesis of increased intestinal permeability during cholera.

Disruption of the integrity of the gut lining has long been considered a possible mechanism underlying the massive diarrhoea of Asiatic cholera. However, the morphology of intestinal epithelium remains unaltered during the disease (Gangarosa, Beisel, Benyajati, Sprinz, and Piyaratn, 1960). The demonstration of low protein content in choleraic stool (Weaver, Johnson, and Phillips, 1948) and intestinal impermeability to polyvinyl pyrrolidone macromolecules (Gordon, 1962) suggests that if membrane changes are occurring they must be in a functional area of epithelium selectively permeable to small molecules. Love (1969) reported a doubling of equivalent pore radius in rabbit ileal loops after infection with Vibrio cholerae. He suggested that increased intestinal permeability to small plasma solutes and ions may play an important role in the accumulation of luminal fluid in cholera.

Treatment of gut mucosa as a single barrier penetrated by right cylindrical pores of uniform dimension permits calculations to be made which express membrane selectivity for the passage of small molecules. The radius of these theoretical channels is called the equivalent pore radius. Given a pair of solutes of dissimilar size, a pore will permit the

\footnotetext{
${ }^{1}$ Reprint requests should be sent to: SEATO Cholera Research Program, NIAID Building 31, room 7A03, National Institutes of Health, Bethesda, Maryland, 20014 USA.

Received for publication 11 January 1972.
}

smaller to pass more readily. As the pore enlarges, it will discriminate less between the two solutes, the ratio of absorption rates approaching unity. Thus, from the ratio of absorption rates of solutes of different sizes an equivalent pore size can be calculated (Renkin, 1954).

Using a technique based on this principle and developed by Fordtran, Rector, Locklear, and Ewton (1967), we have evaluated the permeability and calculated the equivalent pore size of canine and human jejunum during experimental and naturally acquired cholera. The sensitivity and validity of this technique were tested by employing amphotericin B, an antibiotic which is known to affect the permeability of a number of membrane systems (Lichtenstein and Leaf, 1965; Butler, Alling, and Cotlove, 1965).

\section{Methods}

\section{CANINE STUDIES}

Eleven dogs $(15-18 \mathrm{~kg})$ were fasted overnight and anaesthetized with $10 \mathrm{mg} / \mathrm{kg}$ pentobarbital. The jejunum was exposed through a midline incision. Starting $15 \mathrm{~cm}$ distal to the ligament of Treitz two adjacent $20 \mathrm{~cm}$ lengths of jejunum were tied off with umbilical tape in situ, care being taken to preserve normal blood supply. A multiperforated polyethylene catheter was inserted into the full length of each segment. The loops were replaced into the 
abdomen with the catheters leading through the skin. Each loop was washed with $10 \mathrm{ml}$ volumes of physiological saline until clear. All solutions employed in this study were prewarmed to $37^{\circ} \mathrm{C}$. Flux measurements were made by instilling $20 \mathrm{ml}$ of a test solution into each loop. After mixing, $5 \mathrm{ml}$ was withdrawn and the study period was initiated. Ten minutes later the loops were emptied. Between each study period, each segment was washed twice with $10 \mathrm{ml}$ of saline. The composition of the test solution was as follows: $\mathrm{Na} 145, \mathrm{~K} 6, \mathrm{Cl} 126, \mathrm{HCO}_{3} 25$ $\mathrm{m}$-equiv/l, urea 1 and arabinose $2 \mathrm{~m}-\mathrm{mol} / \mathrm{l}$, and polyethylene glycol (PEG) $10 \mathrm{~g} / \mathrm{l} .{ }^{14} \mathrm{C}$-Urea $(5 \mu \mathrm{ci} / \mathrm{m}$ $\mathrm{mol})$ and ${ }^{3} \mathrm{H}$-arabinose $(5 \mu \mathrm{ci} / \mathrm{m}-\mathrm{mol})$ were included in the test solution. Initial and final samples were analysed for PEG, $\mathrm{Na}$, and $\mathrm{K}$ concentrations and activity of ${ }^{14} \mathrm{C}$ and ${ }^{3} \mathrm{H}$.

To determine the effects of amphotericin B, after three control study periods, amphotericin B (15 $\mu \mathrm{g} / \mathrm{ml}$ ) was included in the test solution for three additional periods. For experimental canine cholera studies, following three control observations, cholera toxin (250 mg of NIH lot 001 in $10 \mathrm{ml}$ saline) was instilled into the loop for 15 to 20 minutes. Three hours later when the loop exhibited brisk diarrhoea, three flux observations were made.

STUDIES ON PATIENTS

Seven adult Bengali patients who were inpatients at the Pakistan-SEATO Cholera Research Laboratory with uncomplicated, bacteriologically confirmed cholera were selected for study. Each patient was studied during acute cholera and after recovery. The average time from admission until the cholera study was two days. Convalescent studies in all patients were performed at least one day after complete cessation of diarrhoea. Before the initial study, dehydration and electrolyte imbalance were corrected by intravenous solutions. No other medications were administered. After the patient was clinically stable, a soft, weighted polyethylene tube was passed into the stomach and allowed to progress through the intestine. Upon its appearance at the anus 8-24 hours later, a transintestinal triple-lumen study tube was connected to the oral end of the polyethylene tube and gently pulled into place (Fig. 1) (Kinzie and Hare, 1968). The infusion port, which was located $60 \mathrm{~cm}$ from the incisors, was positioned just beyond the ligament of Treitz. In 10 Bengali patients studied before the position of the infusion port in the jejunum was confirmed radiologically (Taylor, Hare, and Phillips, 1968). The proximal sampling port (P) was $15 \mathrm{~cm}$ and the distal sampling port (D) was 55 $\mathrm{cm}$ caudad to the infusion port. Thus a $15 \mathrm{~cm}$ mixing segment and a $40 \mathrm{~cm}$ study segment were delineated. A fine lumen tube (ID 0.02 in., $0.5 \mathrm{ml}$ dead space) for

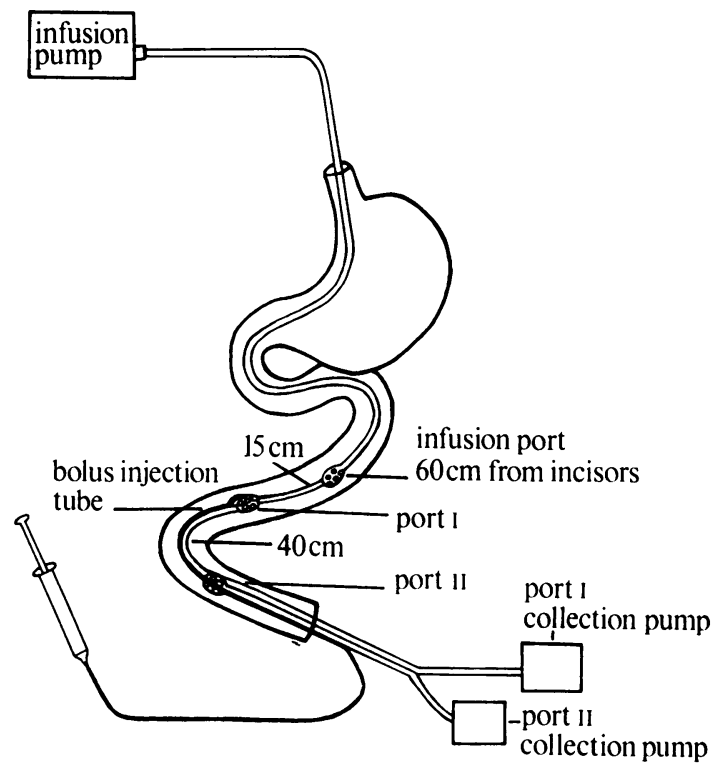

Fig. Transintestinal multilumen tube used in patient studies. Infusion port was positioned in the jejunum beyond the ligament of Treitz $60 \mathrm{~cm}$ from incisors. Proximal sampling port (port I) was $15 \mathrm{~cm}$ caudad and distal sampling port (port II) an additional $40 \mathrm{~cm}$ caudad. These ports delineated a $15 \mathrm{~cm}$ mixing segment and a $40 \mathrm{~cm}$ study segment. Constant perfusion was assured by infusion of a normal jejunal aspirate solution through the infusion port. A bolus of BSP and labelled solutes was injected into port I and sampled from port II.

injection of the test bolus opened at the level of port $P$.

Perfusion solution prepared to approximate the electrolyte content of jejunal aspirate from cholera patients (Banwell, Pierce, Mitra, Brigham, Caranasos, Keimowitz, Fedson, Thomas, Gorbach, Sack, and Mondal, 1970) had the following composition: $\mathrm{Na} 140, \mathrm{~K} 6, \mathrm{Cl} 135, \mathrm{HCO}_{3} 11 \mathrm{~m}$-equiv/l and PEG $10 \mathrm{~g} / \mathrm{l}$. Diaphragm pump infusion rates of $25 \mathrm{ml} / \mathrm{min}$ and $30 \mathrm{ml} / \mathrm{min}$ were used during diarrhoea and recovery experiments, respectively. Because there is net jejunal secretion during cholera and net absorption during convalescence (Table II), the infusion pump rate was adjusted to produce similar mean flow rates. Sampling at a constant rate from proximal and distal study ports was achieved with finger pumps set at $1.5 \mathrm{ml} / \mathrm{min}$ and $7.0 \mathrm{ml} / \mathrm{min}$, respectively. Equilibration infusion lasted for one to two hours. To determine net water movement, 20-minute collections were taken from ports $P$ and $D$, offset by an appropriate mean transit time between the ports (Whalen, Harris, Greenen, and Soergel, 1966). Mean transit time was determined by injection of a bromosulphophthalein (BSP) bolus into port $\mathbf{P}$ 
followed by timed collections from port $D$. The proximal sampling port pump was then stopped and a $1 \mathrm{ml}$ bolus containing BSP and labelled test solutes was quickly injected through the fine lumen tube into the proximal end of the study segment. Laminar streaming was minimized by constant gentle agitation of the patient's abdomen. The effluent from the distal sampling port was collected in one-minute fractions of $7 \mathrm{ml}$. A drop from each sample was placed in an alkalinized microtitre tray for visualization of the BSP transit curve. Collections were continued until all the BSP had passed port D. Each solute pair was studied during at least three such bolus transits, after which the 20-minute collection from both proximal and distal ports was repeated. Each fraction was analysed for labelled solutes. The solutes studied, amount injected, tracer, and molecular radii were:

\begin{tabular}{llll}
\hline & Amount & Label & Radius $A^{1}$ \\
\hline Urea & $1 \mathrm{mM} 5 \mu \mathrm{Ci}$ & ${ }^{14} \mathrm{C}$ & 2.3 \\
Arabinose & $2 \mathrm{mM} 10 \mu \mathrm{Ci}$ & ${ }^{8} \mathrm{H}$ & 3.5 \\
\hline
\end{tabular}

'Schultz and Solomon (1961)

\section{ANALYTICAL METHOD}

Sodium and potassium concentrations were measured with a flame photometer and PEG concentration was determined by a modification of the method of Hyden (1956). ${ }^{14} \mathrm{C}$ and ${ }^{3} \mathrm{H}$ were counted in a Beckman LS-100 liquid scintillation spectrometer. Quench corrections were made by using the channels-ratio method (Davidson, 1958).

\section{CALCULATIONS}

Net water and electrolyte fluxes into or out of the test segment were calculated by standard methods (Soergel, Whalen, and Harris, 1968). Relative absorption rates of ${ }^{14} \mathrm{C}$-urea and ${ }^{3} \mathrm{H}$-arabinose were compared by plotting a ratio of ${ }^{14} \mathrm{C}$ to ${ }^{3} \mathrm{H}$ counts per minute in each sample against time. The ratio of solute concentrations was found to decrease by first order kinetics giving a straight line on a semi-log plot. This relationship can be described by the equation $R_{t}=R_{0} e^{-k t}$, where $R_{t}$ is the concentration ratio of urea to arabinose at any time $t$. The slope of this line (k) is directly proportional to the relative absorption rates of the two solutes from the bolus.

In the dog studies absorption rates for ${ }^{14} \mathrm{C}$-urea and ${ }^{3} \mathrm{H}$-arabinose were calculated individually by the method of Berger and Steele (1958). Fractional absorption rate $(\mathrm{K})$ was calculated from the following equation:

$$
K=\frac{-\ln \left(\mathbf{A}_{t} / \mathbf{A}_{0}\right)}{t}
$$

$\mathrm{K}=$ fractional solute absorption rate (per minute)

$A_{0}=$ amount of radioactivity of initial sample

$A_{t}=$ amount of radioactivity of final sample

$\mathrm{t}=$ time (10 minutes)

The ratio of these individual rates (arabinose/urea) provided a measure of relative selectivity.

The equation derived by Renkin (1954) for restricted diffusion was applied to these ratios to calculate equivalent pore size of the membrane. Renkin's equation relates diffusion area (A) to molecular radius (a) and pore radius (r). The disappearance ratio of two solutes such as arabinose and urea is given by:

$$
\begin{aligned}
A_{1} / A_{2}= & {\left[2\left(1-a_{1} / r\right)^{2}-\left(1-a_{1} / r\right)^{4}\right] } \\
& {\left[1-2 \cdot 104 a_{1} / r+2 \cdot 09\left(a_{1} / r\right)^{3}-0.95\left(a_{1} / r\right)^{5}\right] / } \\
& {\left[2\left(1-a_{2} / r\right)^{2}-\left(1-a_{2} / r\right)^{4}\right] } \\
& {\left[1-2 \cdot 104 a_{2} / r+2 \cdot 09\left(a_{2} / r\right)^{3}-0.95\left(a_{2} / r\right)^{5}\right] }
\end{aligned}
$$

where $r \quad=$ equivalent pore radius

$$
\mathrm{a}_{1}=\text { molecular radius of arabinose }(3 \cdot 5 \AA)
$$$$
\mathrm{a}_{2}=\text { molecular radius of urea }(2 \cdot 3 \AA)
$$

$A_{1} / A_{2}=$ ratio of disappearance rate of arabinose with respect to that of urea

$A_{1} \quad=$ relative diffusion area for arabinose

$A_{2} \quad=$ relative diffusion area for urea

\section{Results}

Paired studies in 10 dog loops revealed a significant $33 \%$ increase in calculated pore size following intraluminal application of amphotericin B (Table I). Jejunal permeability was increased as seen by the faster absorption rates of urea and arabinose during drug exposure. The ability of the jejunum to discriminate between these two solutes of differing molecular size was reduced, as was seen by the larger calculated equivalent pore in each of the 10 study loops.

During experimental canine cholera, the selectivity of the jejunum did not change significantly, as indicated by the unaltered ratio of arabinose to urea absorption rates and calculated pore size (Table I). However, the individual rates of urea and arabinose absorption were reduced. This suggests decreased membrane permeability without changes in membrane selectivity.

Stool output and net water fluxes during cholera and convalescence for seven patients are shown in Table II. The severity of disease is reflected by the fact that six of the seven patients had a stool output over the course of the disease equal to or in excess of their total body weight. Net stool loss during the acute study averaged $14 \mathrm{ml} / \mathrm{kg} / \mathrm{hr}$. In the first three patients the disappearance rate of three solute pairs 


\begin{tabular}{|c|c|c|c|c|c|c|}
\hline & \multirow[t]{2}{*}{ No. of Loops } & \multicolumn{2}{|c|}{ Absorption Rate (\% absorbed per min) } & \multirow{2}{*}{$\begin{array}{l}\text { Ratio of: } \\
\text { Arabinose/Urea }\end{array}$} & \multirow{2}{*}{$\begin{array}{l}\mathrm{H}_{2} \mathrm{O} \text { Movement } \\
(\mathrm{ml} \text { per } 10 \mathrm{~min})\end{array}$} & \multirow{2}{*}{$\begin{array}{l}\text { Calculated } \\
\text { Equivalent Pore } \\
\text { Radius (Angstroms) }\end{array}$} \\
\hline & & ${ }^{14} \mathrm{C}$-urea & ${ }^{8} \mathrm{H}$-arabinose & & & \\
\hline $\begin{array}{l}\text { Control } \\
\text { Amphotericin B }\end{array}$ & $\begin{array}{l}10 \\
10\end{array}$ & $\begin{array}{l}5.7 \pm 0.56 \\
6.1 \pm 0.87\end{array}$ & $\begin{array}{r}1.46 \pm 0.18 \\
2.7 \pm 0.56\end{array}$ & $\begin{array}{l}0.25 \pm 0.01 \\
0.41 \pm 0.03\end{array}$ & $\begin{array}{l}-1.74 \pm 0.17 \\
-3.16 \pm 0.28\end{array}$ & $\begin{array}{l}6.3 \pm 0.01 \\
8.6 \pm 0.46\end{array}$ \\
\hline $\begin{array}{l}\text { Control } \\
\text { Cholera toxin }\end{array}$ & $\begin{array}{l}11 \\
11\end{array}$ & $\begin{array}{l}5.2 \pm 0.57 \\
2.8 \pm 0.40\end{array}$ & $\begin{array}{l}1.4 \pm 0.16 \\
0.7 \pm 0.10\end{array}$ & $\begin{array}{l}0.28 \pm 0.02 \\
0.28 \pm 0.03\end{array}$ & $\begin{array}{l}-1.30 \pm 0.13 \\
+3.6 \pm 0.36\end{array}$ & $\begin{array}{l}6.8 \pm 0.30 \\
6.8 \pm 0.40\end{array}$ \\
\hline
\end{tabular}

Table I Permeability and selectivity of canine jejunal loops exposed to amphotericin $B$ and cholera toxin ${ }^{1}$

Amphotericin $B(15 \mu \mathrm{g} / \mathrm{ml})$ significantly increased individual absorption rates of urea and arabinose $(P<0.01)$. This agent also altered membrane selectivity as expressed by change of equivalent pore radii from $6.3 \pm 0.01$ to $8.6 \pm 0.46(P<0.01)$. During brisk diarrhoea three hours after cholera toxin challenge ( $250 \mathrm{mg}$ NIH lot 001 in $10 \mathrm{ml}$ saline) there was no significant alteration of selectivity or equivalent pore size. Individual absorption rates of urea $(P<0.05)$ and arabinose $(P<0.01)$ were markedly depressed. Significance was determined by pair analysis. Positive sign was movement of water into the loop.

\begin{tabular}{|c|c|c|c|c|c|}
\hline \multirow[t]{2}{*}{ Patient } & \multirow[t]{2}{*}{ Patient Weight $(k g)$} & \multirow{2}{*}{$\begin{array}{l}\text { Total Stool Output } \\
\text { during Hospitalization } \\
(l)\end{array}$} & \multirow{2}{*}{$\begin{array}{l}\text { Stool Output during } \\
\text { Acute Study } \\
(\mathrm{ml} / \mathrm{kg} / \mathrm{hr})\end{array}$} & \multicolumn{2}{|c|}{$\begin{array}{l}\text { Net Water Movement across } 40 \mathrm{~cm} \text { Segment } \\
(\mathrm{ml} / \mathrm{min})\end{array}$} \\
\hline & & & & Acute & Convalescent \\
\hline $\begin{array}{l}1 \\
2 \\
3 \\
4 \\
5 \\
6 \\
7\end{array}$ & $\begin{array}{l}42 \\
50 \\
41 \\
33 \\
37 \\
39 \\
33\end{array}$ & $\begin{array}{l}31 \cdot 7 \\
53 \cdot 3 \\
56 \cdot 6 \\
34 \cdot 5 \\
89 \cdot 0 \\
51 \cdot 1 \\
32 \cdot 8\end{array}$ & $\begin{array}{r}8.5 \\
15.5 \\
22.0 \\
12.5 \\
13 \cdot 5 \\
12.0 \\
15.0\end{array}$ & $\begin{array}{l}+2.6 \\
+3.7 \\
+3.2 \\
+1 \cdot 1 \\
+1.1 \\
+4 \cdot 1 \\
+2.0\end{array}$ & $\begin{array}{l}-3.0 \\
-2.0 \\
-3.0 \\
-1.5 \\
-1.9 \\
-1.5 \\
-2.0\end{array}$ \\
\hline Mean \pm SEM & $39 \cdot 3 \pm 2 \cdot 2$ & $49.8 \pm 7.6$ & $14 \cdot 1 \pm 1 \cdot 6$ & $+2.5 \pm 0.4$ & $-2 \cdot 1 \pm 0.2$ \\
\hline
\end{tabular}

Table II Stool output and segmental water flux in seven cholera patients

Stool output during study was equal to stool output plus sample volume minus perfusion input during course of acute study. Positive sign was movement of water into the segment and minus was movement out of segment.

\begin{tabular}{|c|c|c|c|c|}
\hline \multirow[t]{2}{*}{ Patient } & \multicolumn{2}{|c|}{ Relative Absorption Rates: Arabinose/Urea } & \multicolumn{2}{|c|}{ Equivalent Pore Radius (Angstroms) } \\
\hline & Acute Cholera & Recovery & Acute Cholera & Recovery \\
\hline $\begin{array}{l}1 \\
2 \\
3 \\
4 \\
5 \\
6 \\
7\end{array}$ & $\begin{array}{l}0.24 \\
0.17 \\
0.33 \\
0.32 \\
0.53 \\
0.27 \\
0.50\end{array}$ & $\begin{array}{l}0.33 \\
0.15 \\
0.38 \\
0.50 \\
0.48 \\
0.41 \\
0.51\end{array}$ & $\begin{array}{r}6.2 \\
5.4 \\
7 \cdot 3 \\
7 \cdot 2 \\
10 \cdot 2 \\
6.6 \\
9.8\end{array}$ & $\begin{array}{r}7 \cdot 3 \\
5 \cdot 2 \\
8 \cdot 0 \\
9 \cdot 8 \\
9 \cdot 5 \\
8 \cdot 5 \\
10 \cdot 0\end{array}$ \\
\hline Mean \pm SEM & $0.34 \pm 0.04$ & $0.39 \pm 0.04$ & $7 \cdot 5 \pm 0.6$ & $8.3 \pm 0.6$ \\
\hline
\end{tabular}

Table III Jejunal selectivity and calculated pore size of seven patients during cholera and after recovery ${ }^{1}$

${ }^{1}$ Selectivity as expressed by ratio of urea and arabinose absorption rates and calculated equivalent pore size (7.5 \pm 0.6 to $8.3 \pm 0.6$ did not significantly change from cholera to recovery. Each ratio is an average of three or four independent determinations during a single study.

was examined: urea/arabinose, urea/mannitol, and erythritol/mannitol. Because the absorption rate of mannitol was very low under our study conditions, only the urea/arabinose pair was examined in the last four studies. Table III shows the relative disappearance rates of arabinose and urea and the calculated equivalent pore radii during cholera and convalescence. Effective pore size, calculated from the disappearance ratio, was not significantly different from cholera to convalescence.

\section{Discussion}

When the laws governing macroscopic flow are applied to the movement of inactively transported molecules through a simple membrane with uniform pores, many aspects of the behaviour of biological membranes exposed to aqueous solutions can be predicted and understood. Solomon (1961) has discussed the assumptions and advantages inherent in such a model. Although the absorption rate of an 
individual solute is a function of membrane permeability, the relative absorption rate of a given solute pair is an expression of membrane selectivity. A calculated equivalent pore radius is a mathematical description of this selectivity. This approach has been useful in the study of a variety of synthetic and biological membranes (Renkin, 1954; Solomon, 1961). Increased pore size has been observed in artificial cellulose membranes after stretching, and the application of antidiuretic hormone to toad bladder results in increased membrane permeability and pore size (Fordtran et al, 1967).

In order to examine the sensitivity and validity of the technique employed in this study, canine jejunum was exposed to amphotericin B. This antibiotic, which binds to membrane sterol groups, has been shown to increase toad bladder and red cell permeability to electrolytes, water, and urea (Lichtenstein and Leaf, 1965; Butler et al, 1965). We have demonstrated that this agent has marked permeability and selectivity effects on intestinal epithelium. Amphotericin B caused an enhancement of permeability as indicated by increased urea and arabinose absorption rates and an increase in pore size of canine jejunum from $6 \cdot 3$ to $8.5 \AA$. Thus our technique of measuring individual and relative solute absorption rates is sensitive to amphotericin B-induced membrane changes.

During experimental canine cholera, no significant change in equivalent pore size was observed. We have also demonstrated no alteration of equivalent pore radii in human jejunum from cholera to recovery. Our calculated mean pore radius in human jejunum of $8.3 \AA$ during convalescence is similar to the values of 7.0 to 8.5 and $7.9 \AA$ reported for normal western man by Fordtran, Rector, Ewton, Soter, and Kinney (1965) and Soergel et al (1968).

Individual absorption rates of urea and arabinose, however, were significantly depressed in association with canine cholera. This diminished absorption, unaccompanied by changes of selectivity, is compatible with a diminution of intestinal permeability. In terms of the pore hypothesis, this would represent a reduction in the number of pores without changes in their dimension. This interpretation, however, should not be regarded as conclusive since reduced absorption rates may be secondary to reversal of bulk water movement from absorption to secretion. Accurate measurement of individual absorption rates in the human studies was beyond the capability of our technique. One important variable, intestinal surface area delineated by the $40 \mathrm{~cm}$ study segment, could not be adequately controlled from one study to another, even in the same patient. The ratio of absorption rates, however, remained unaffected since both solutes were measured simultaneously and variables such as intestinal surface area, flow characteristics, and pore density should theoretically influence both solutes equally.

In contrast to our findings, Love (1969) has reported increased intestinal permeability in rabbit ileal loops after infection with Vibrio cholerae. Measuring bulk water flow in response to osmotic gradients established with hypertonic mannitol, erythritol, ' and urea solutions, he calculated a doubling of pore size during cholera. It is possible that his incubation period of 10 to 12 hours with a viable organism between control and cholera observations could artefactually induce membrane permeability changes. Interestingly, our study suggests that increased luminal border permeability facilitates net absorption of solutes rather than secretion. This is consistent with Finn's observation that exposure of toad bladder mucosa to amphotericin B results in increased sodium movement from lumen into the cell (Finn, 1968). In addition, sugars and amino acids, by enhancing substrate-dependent sodium influx into the cell, stimulate the lumen-toplasma transport of sodium (Goldner, Schultz, and Curran, 1969). Thus the luminal barrier to the entry of sodium to the cell appears into be an important step of transmucosal sodium transport (Schultz and Zalusky, 1964), and by increasing the permeability of this barrier with amphotericin B net absorption was enhanced.

These data contradict the hypothesis that the pathogenesis of choleraic diarrhoea may be mediated by increased intestinal permeability.

We thank Drs Kendrick Hare, Ruth Hare, Joseph L. Kinzie, and David Nalin for their guidance and helpful comments.

The Pakistan-SEATO Cholera Research Laboratory was part of the SEATO cholera research programme and was supported by the US Agency for International Development, Department of State, the National Institutes of Health, and Center for Disease Control of the Department of Health, Education and Welfare, and by the Governments of Pakistan, the United Kingdom, and other SEATO nations. The NIH Cholera Advisory Committee coordinated the research programme. These studies were supported in part by research agreement no. 196802 between the National Institutes of Health, Bethesda, Maryland, USA, and the PakistanSEATO Cholera Research Laboratory, Dacca, East Pakistan.

\section{References}

Banwell, J. G., Pierce, N. F., Mitra, R. C., Brigham, K. L., Caranasos, G. J., Keimowitz, R. I., Fedson, D. S., Thomas, J., Gorbach, S. L., Sack, R. B., and Mondal, A. (1970). Intestinal fluid and 
electrolyte transport in human cholera. J. clin. Invest., 49, 183-195.

Berger, E. Y., and Steele, J. M. (1958). The calculation of transfer rates in two compartment systems not in dynamic equilibrium. J. gen. Physiol., 41, 1135-1152.

Butler, W. T., Alling, D. W., and Cotlove, E. (1965). Potassium loss from human erythrocytes exposed to amphotericin B. Proc. Soc. exp. Biol. (N.Y.), 118, 297-300.

Davidson, J. D. (1958). Homogeneous counting systems. In Liquid Scintillation Counting, edited by C. G. Bell and F. N. Hayes, p. 88. Pergamon Press, Oxford.

Finn, A. L. (1968). Separate effects of sodium and vasopressin on the sodium pump in toad bladder. Amer. J. Physiol., 215, 849-856.

Fordtran, J. S., Rector, F. C., Ewton, M. F., Soter, N., and Kinney, J. (1965). Permeability characteristics of the human smal intestine. J. clin. Invest., 44, 1935-1944.

Fordtran, J. S., Rector, F .C., Jr., Locklear, T. W., and Ewton, M. F. (1967). Water and solute movement in the small intestine of patients with sprue. J. clin. Invest., 46, 287-298.

Gangarosa, E. J., Beisel, W. R., Benyajati, C., Sprinz, H., and Piyaratn, P. (1960). The nature of the gastrointestinal lesion in Asiatic cholera and its relation to pathogenesis: a biopsy study. Amer. J. trop. Med., 9, 125-135.

Goldner, A. M., Schultz, S. G., and Curran, P. F. (1969). Sodium and sugar fluxes across the mucosal border of rabbit ileum. J. gen. Physiol., 53, 362-383.

Gordon, R. S. (1962). The failure of Asiatic cholera to give rise to 'exudative enteropathy'. In SEATO Conference on Cholera, 1960: Papers Presented and Summaries of Discussions, pp. 54-55. SEATO, Bangkok.

Hyden, S. (1956). A turbidometric method for the determination of higher polyethylene glycols in biological materials. $K$. LantbrHogsk. Annlr., 22, 139-145.
Kinzie, J. L., and Hare, W. K. (1968). Measurement of intestinalpermeability in man by diffusion ratio technique. (Abstr.). Fed. Proc., 27, 385.

Lichtenstein, N. S., and Leaf, A. (1965). Effect of amphotericin B on the permeability of the toad bladder. J. clin. Invest., 44, 13281342.

Love, A. H. G. (1969). Permeability characteristics of the cholera infected small intestine. Gut, 10, 105-107.

Renkin, E. M. (1954). Filtration, diffusion, and molecular sieving through porous cellulose membranes. J. gen. Physiol., 38, 225-243.

Schultz, S. G., and Solomon, A. K. (1961). Determination of the effective hydrodynamic radii of small molecules by viscometry. J. gen. Physiol., 44, 1189-1199.

Schultz, S. G., and Zalusky, R. (1964). Ion transport in isolated rabbit ileum. II. The interaction between active sodium and active sugar transport. J. gen Physiol., 47, 1043-1059.

Soergel, K. H., Whalen, G. E., and Harris, J. A. (1968). Passive movement of water and sodium across the human small intestinal mucosa. J. appl. Physiol., 24, 40-48.

Solomon, A. K. (1961). Measurement of the equivalent pore radius in cell membranes. In Membrane Transport and Metabolism, edited by A. Kleinzeller and A. Kotyk, pp. 94-99. Academic Press, New York.

Taylor, J. O., Hare, R. H., and Phillips, R. A. (1968). Measurement of sodium fluxes in human small intestine. (Abstr.). Fed. Proc., $27,386$.

Weaver, R. H., Johnson, M. K., and Phillips, R. A. (1948). Biochemical studies of cholera. J. Egypt. publ. Hlth Ass., 24, 5-14.

Whalen, G. E., Harris, J. A., Greenen, J. E., and Soergel, K. H. (1966). Sodium and water absorption from the human small intestine: the accuracy of the perfusion method. Gastroenterology, 51, 975-984. 